\title{
A Research on the Relationship between Urban Households' Income and Expenditure in Hainan
}

\author{
Junmei Zhou, Defei Zhang \\ School of Mathematics and Statistics, Hainan Normal University, Haikou, China \\ Department of Mathematics, Honghe University, Mengzi, China \\ Email: hnzhoujunmei@163.com,zhdefei@163.com
}

Received 2012

\begin{abstract}
APC (Average Propensity to Consume) refers to the ratio of dividing consumption by income during the same period, which reflects the percentage of consumption in current residents' income. This paper analyses the APC and builds up models about the dynamic relationships between urban residents' income and consumption expenditure in Hainan, with panel data model, choosing per capita annual disposable income as explanatory variable, per capita living annual expenditure as response variable, and data from the year of 2004 to 2010. The research shows that different income levels bring different impacts on consumption, and provides theories of adjusting the consumption structure, expanding domestic demand and promoting the economy development.
\end{abstract}

Keywords: Panel Data Model; Income; Consumption; Urban Resident

\section{Introduction}

With the great opportunity of enhancing the International Tourism Island to the national strategy, it is important for Hainan to promote further the policies of reform and opening-up, emphasize on the transformation of the economic development mode, speed up the adjustment of the economic structure and create a new situation in scientific development. Research on urban residents' consumer behavior helps to know consumption information of the province, make relevant policy promoting consumption and drive the development of the economy in Hainan.

Both domestic and overseas academicians made large amounts of researches about the relationship between income gap and consumer demand. Blinder(2002): narrowing the income gap will not increase consumption [1]. Valley, Philips (2003): consumption, levels of economic development and income inequality may be of relevance [2]. Musgrove(2005): while urban income gap affects consumption markedly in high-income countries, it does not happen in low-income countries [3]. Sun Feng, Yi Danhui(2000): utilizes the panel-data model to discuss the effects which income distribution and expectation have exerted on Chinese urban households consumption structure. Results show that income level has a great influence on the spending structure of urban residents, and the difference of consumer behavior at different ranks is large[4]. Li Jun(2003): both income gap and income level are important factors that affect consumption[5]. Zhang Yi ,Hu Ridong(2003): urban residents' yawning income gap has significant effects on inhibiting general consumption trend[6]. Chen Leyi(2005): income gap is the main reason of lack of consumer demand.The premise of inecreasing consumption demand and level is doing everying to raise income of common urban and rural residents, especially of low income households[7].

The next parts of this paper are as follows: the second part analyzes the current situation of income gap and consumer structure in Hainan, the third part introduces panel data model, the fourth part is empirical analysis and some conclusions are obtained; the fifth part is conclusion.

\section{Analysis of Current Situation}

In 2010, the per capita disposable income of urban households is RMB 15581 with an increase of 13.3 percent over the previous year in Hainan. The per capita living expenditure of urban residents is RMB 10927 with an increase of 8.3 percent. The overall level of local comsumer price indices increased by 4.8 percent over the previous year. All residence price indices of building, decoration materials, renting, water, electricity and fuel advanced noticeably, taking its gains for the year to 9.7 percent. The food price increased by 7.6 percent and retail price rose by 4.6 percent.

APC refers to the ratio of dividing consumption by income during the same period, which reflects the percent- 
age of consumption in current residents' income. Expenditure for consumption of urban households includes expenses on food, clothing, HFAC(household facilities, articles and services), HCMS (health care and medical

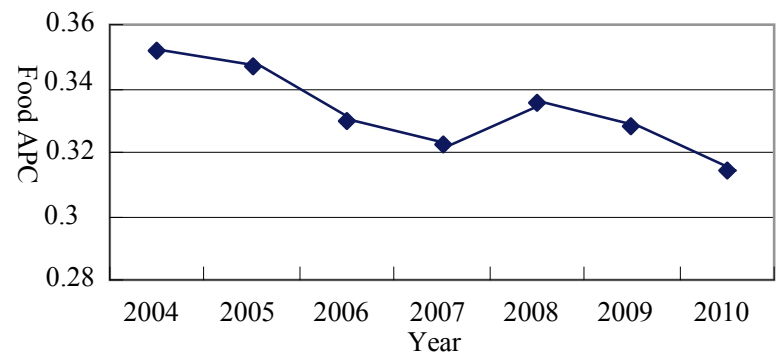

Figure 1. Average Propensity to Consume of Food

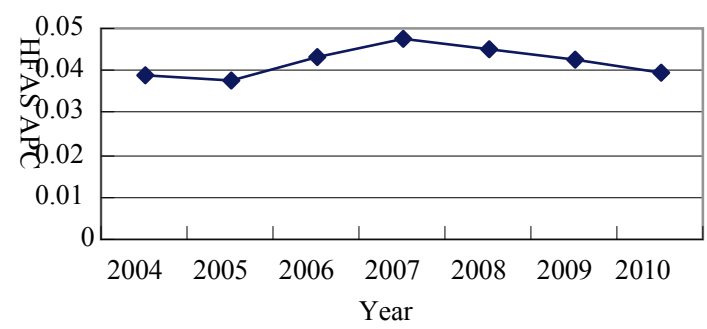

Figure 3. Average Propensity to Consume of HFAS

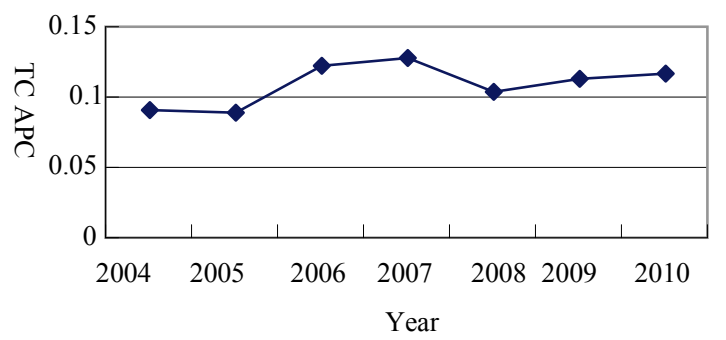

Figure 5. Average Propensity to Consume of TC

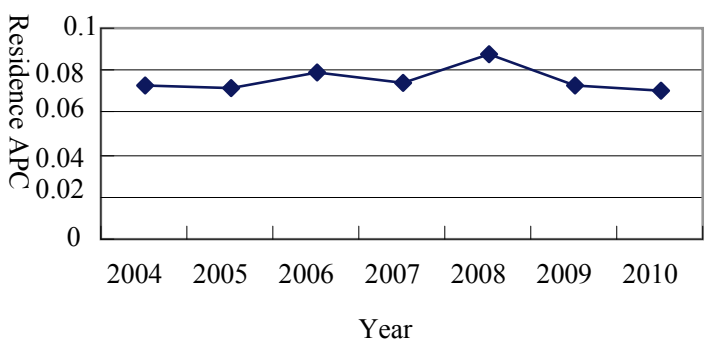

Figure 7. Average Propensity to Consume of Residence

services), TC(transport and communications), RECS (recreation, education and cultural services), Residence and MCS(miscellaneous commodities and services).
According to the yearbook of Hainan province (20052011) [8], we have got Figure 1 to Figure 8.

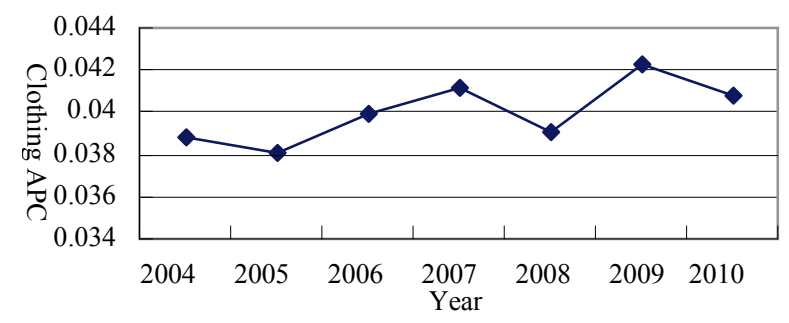

Figure 2. Average Propensity to Consume of Clothing

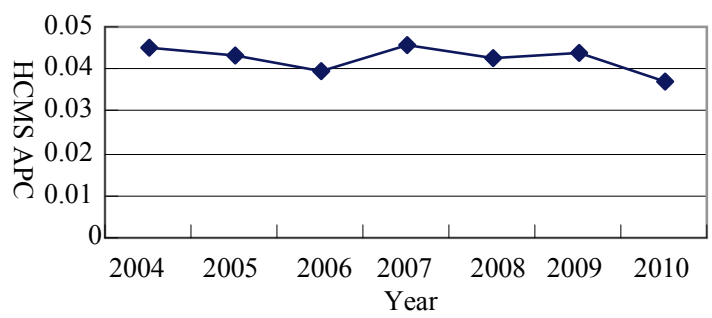

Figure 4. Average Propensity to Consume of HCMS

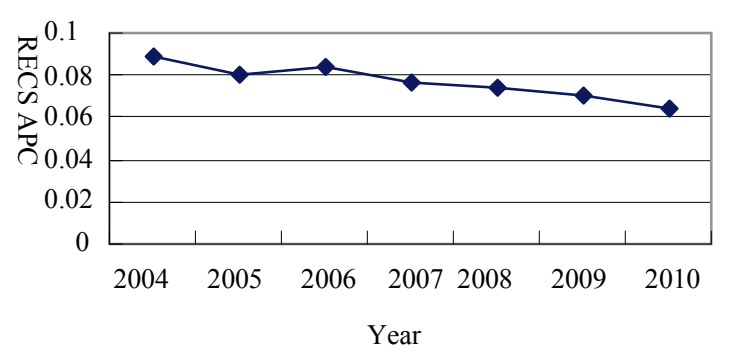

Figure 6. Average Propensity to Consume of RECS

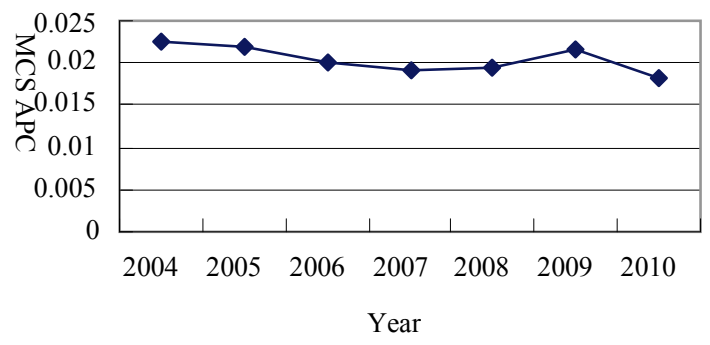

Figure 8. Average Propensity to Consume of MCS

From the average propensity to consume to see, average propensity to consume of TC is the highest, which in-dicates that urban residents' underlying consumer dema- nd focuses on Food. As income levels increase, food ex- penditures drops year by year. Second is av- 
erage propen- sity to consume of TC and third is that of Residence. Av-erage propensity to consume of Clothing and HCMS firstly descend and then ascend, which is a cycle change. Average propensity to consume of RECS comes down year by year.

\section{Panel Data Model}

A longitudinal, or panel, data set is one that follows a given sample of individuals over time, and thus provides multiple observations on each individual in the sample.

Panel data usually give the researchers a large number of data points increasing the degrees of freedom and reducing the collinearity among explanatory variables hence improving the efficiency of econometric estimates. More importantly, longitudinal data allow a researcher to analyze a number of important economic questions that cannot be addressed using cross-sectional or time series data sets[9]. The use of panel data also provides a means of resolving or reducing the magnitude of a key econometric problem that often arises in empirical studies, namely, the often heard assertion that the real reason one finds (or does not find) certain effects is the presence of omitted (mismeasured or unobserved) variables that are correlated with explanatory variables. By utilizing information on both the intertemporal dynamics and the individuality of the entities being investigated, one is better able to control in a more natural way for the effects of missing or unobserved variables. Panel data models have become increasingly popular among applied researchers due to their heightened capacity for capturing the complexity of human behavior over the years.

Suppose we have sample observations of characteristics of $N$ inividuals over $T$ time periods denoted by $y_{i t}$, then panel data model can be defined as follows:

$$
\begin{aligned}
y_{i t}=\alpha_{i t}^{*}+\beta_{i t}^{\prime} x_{i t}+u_{i t} \quad i=1, \ldots, N \\
t=1, \ldots, T
\end{aligned}
$$

where $\alpha_{i t}^{*}$ and $\beta_{i t}^{\prime}=\left(\beta_{1 i t}, \beta_{2 i t}, \ldots, \beta_{K i t}\right)$ are $1 \times 1$ and $1 \times K$ vectors of constants that vary across $i$ and $t$, respectively; $x_{i t}^{\prime}=\left(x_{1 i t}, \ldots, x_{K i t}\right)$ is a $1 \times K$ vector of exogenous variables, and $u_{i t}$ is the error term with

mean zero and constant variance $\sigma^{2}$.

For parameters allow for differences in behavior across individuals as well as over time, a panel data model with observations of $y$ depending on a vector of characteristics $x$ can be written in the following form[ 9]: 3.1). Slope coefficients are constant, and the intercept varies over individuals:

$$
y_{i t}=\alpha_{i}^{*}+\sum_{k=1}^{K} \beta_{k} x_{k i t}+u_{i t}, \quad i=1, \ldots, N
$$

$$
t=1, \ldots, T
$$

3.2). Slope coefficients are constant, and the intercept varies over individuals and time:

$$
\begin{array}{r}
y_{i t}=\alpha_{i t}^{*}+\sum_{k=1}^{K} \beta_{k} x_{k i t}+u_{i t}, \quad i=1, \ldots, N \\
t=1, \ldots, T
\end{array}
$$

3.3). All coefficients vary over individuals:

$$
\begin{array}{r}
y_{i t}=\alpha_{i}^{*}+\sum_{k=1}^{K} \beta_{k i} x_{k i t}+u_{i t}, \quad i=1, \ldots, N \\
t=1, \ldots, T
\end{array}
$$

3.4). All coefficients vary over time and individuals:

$$
\begin{array}{r}
y_{i t}=\alpha_{i t}^{*}+\sum_{k=1}^{K} \beta_{k i t} x_{k i t}+u_{i t}, \quad i=1, \ldots, N \\
t=1, \ldots, T
\end{array}
$$

Models with constant slopes and variable intercepts [suc$h$ as (3.1) and (3.2)] are most widely used when analyzing panel data because they provide simple yet reasonably general alternatives to the assumption that parameters take values common to all agents at all times. In this paper, we study model (3.2) which can be rewrited as follows:

$$
y_{i t}=\alpha_{0}+\alpha_{i}+\alpha_{t}+x_{i t} \beta+u_{i t},
$$

$\alpha_{0}$ : mean intercept;

$\alpha_{i}$ : factor that varies across individual units but does not vary over time;

$\alpha_{t}$ : factor that varies over time but does not across individual units.

To estimate $\alpha_{0}, \alpha_{i}, \alpha_{t}$ and $\beta$, we utilize the restriction

$$
\sum_{i=1}^{N} \alpha_{i}=0, \sum_{t=1}^{T} \alpha_{t}=0
$$

and take two steps.

Step 1. Eliminate the individual effect $\alpha_{i}$ and time effect $\alpha_{t}$. Let

$$
\begin{aligned}
& y_{i}=\frac{1}{T} \sum_{t=1}^{T} y_{i t}, x_{i}=\frac{1}{T} \sum_{t=1}^{T} x_{i t}, u_{i}=\frac{1}{T} \sum_{t=1}^{T} u_{i t} \\
& y_{t}=\frac{1}{N} \sum_{i=1}^{N} y_{i t}, x_{t}=\frac{1}{N} \sum_{i=1}^{N} x_{i t}, u_{t}=\frac{1}{N} \sum_{i=1}^{N} u_{i t} \\
& y=\frac{1}{N T} \sum_{i=1}^{N} \sum_{t=1}^{T} y_{i t}, x=\frac{1}{N T} \sum_{i=1}^{N} \sum_{t=1}^{T} x_{i t} \quad u=\frac{1}{N T} \sum_{i=1}^{N} \sum_{t=1}^{T} u_{i t} .
\end{aligned}
$$

Hence

$$
\begin{gathered}
y_{i}=\alpha_{0}+\alpha_{i}+x_{i} \beta+u_{i}, \\
y_{t}=\alpha_{0}+\alpha_{t}+x_{t} \beta+u_{t}, \\
y=\alpha_{0}+x \beta+u .
\end{gathered}
$$

and 


$$
\begin{array}{r}
y_{i t}-y_{i}-y_{t}+y=\beta\left(x_{i t}-x_{i}-x_{t}+x\right)+ \\
\left(u_{i t}-u_{i}-u_{t}+u\right)
\end{array} .
$$

Then the OLS(ordinary least squares) estimator of $\beta$ is

$$
\hat{\beta}=\frac{\sum_{i=1}^{N} \sum_{t=1}^{T}\left(y_{i t}-y_{i}-y_{t}+y\right)\left(x_{i t}-x_{i}-x_{t}+x\right)}{\sum_{i=1}^{N} \sum_{t=1}^{T}\left(x_{i t}-x_{i}-x_{t}+x\right)^{2}},
$$

and $\hat{\alpha}_{0}=y-\hat{\beta} x$.

Step 2. By subtracting (9) from (7) we have

$$
y_{i}-y=\alpha_{i}+\hat{\beta}\left(x_{i}-x\right) \text {, }
$$

Then

$$
\hat{\alpha}_{i}=\left(y_{i}-y\right)-\hat{\beta}\left(x_{i}-x\right) \text {. }
$$

By subtracting (9) from (8) we get

$y_{t}-y=\alpha_{t}+\hat{\beta}\left(x_{t}-x\right)$,

then

$$
\hat{\alpha}_{t}=\left(y_{t}-y\right)-\hat{\beta}\left(x_{t}-x\right) .
$$

\section{Empirical Analysis}

This paper will build up panel data models between income gap and various consumer spending as follows:

$$
\begin{array}{r}
y_{i t}=\alpha_{0}+\alpha_{i}+\alpha_{t}+x_{i t} \beta+u_{i t} \quad i=1, \ldots, N \\
t=1, \ldots, T,
\end{array}
$$

$y_{i t}$ : per capita consumption expenditure of residents in income group $i$ at time $t$ with the unit of currency RMB; $x_{i t}$ : per capita income of residents in income group $i$ at time $t$ with the unit of currency RMB;

$\alpha_{i}$ : parameter that varies across income gap but does not vary over time;

$\alpha_{t}$ : parameter that varies over time but does not across income level;

$u_{i t}$ : the error term.

According to the income standard, we divide urban households into seven income groups: lowest, low, lower middle, middle, upper middle, high and highest. All the statistics is from the year book of Hainan(2005-2011) and adjusted by consumer price indices by category in order to remove the effects of higher prices. Eight consumption models are established as follows by using the Eviews software[10].

4.1) Total Expenditure Model

$$
y_{i t}^{(1)}=1834.67+0.582 x_{i t}+\widehat{\alpha}_{i}^{(1)}+\widehat{\alpha}_{t}^{(1)}
$$

4.2) Food Consumption Model

$$
y_{i t}^{(2)}=2480.70+0.101 x_{i t}+\widehat{\alpha}_{i}^{(2)}+\hat{\alpha}_{t}^{(2)}
$$

4.3) Clothing Consumption Model

$$
y_{i t}^{(3)}=139.89+0.029 x_{i t}+\widehat{\alpha}_{i}^{(3)}+\widehat{\alpha}_{t}^{(3)}
$$

4.4) HFAS Consumption Model

$$
y_{i t}^{(4)}=34.58+0.040 x_{i t}+\hat{\alpha}_{i}^{(4)}+\hat{\alpha}_{t}^{(4)}
$$

4.5) HCMS Consumption Model

$$
y_{i t}^{(5)}=355.62+0.014 x_{i t}+\hat{\alpha}_{i}^{(5)}+\hat{\alpha}_{t}^{(5)}
$$

4.6 ) TC Consumption Model

$$
y_{i t}^{(6)}=-1409.12+0.237 x_{i t}+\widehat{\alpha}_{i}^{(6)}+\hat{\alpha}_{t}^{(6)}
$$

4.7) RECS Consumption Model

$$
y_{i t}^{(7)}=306.84+0.056 x_{i t}+\hat{\alpha}_{i}^{(7)}+\hat{\alpha}_{t}^{(7)}
$$

4.8) Residence Consumption Model

$$
y_{i t}^{(8)}=-246.066+0.094 x_{i t}+\hat{\alpha}_{i}^{(8)}+\hat{\alpha}_{t}^{(8)}
$$

The calculation of $\alpha_{i}$ is in Table 1, and $\alpha_{t}$ in Table 2.

From Table 1, it is clear that income level produces a great influence on the consumption structure of urban residents. In term of total e xpenditure, values of $\alpha_{i}$ in high and highest income households are more than 0 while others less than 0 , which shows that high-income group residents have stronger buying motives than low-income group residents. By the look of various expenditure category, values of $\alpha_{i}$ in lowest, low and lower middle income households are less than 0 , which indicates that their basic needs can not be satisfied. However, food needs in income households above middle have been satisfied. The same situation holds for HCMS expenditure. For people in lowest, low, lower middle and middle income households, values of $\alpha_{i}$ related to TC and Residence expending are more than 0 . In this case, their basic needs cannot be satisfied, their expenditure elasticity of luxuries is very small, their expenditure elasticity of luxuries is very small, compared to people in high and highest income group.

According to Table 2, there were sharply increase trends in total expenditure, food, clothing and HCMS 
J. ZHOU, D. ZHANG

Table 1. Calculation of income level factor $\alpha_{i}$

\begin{tabular}{|c|c|c|c|c|c|c|c|c|}
\hline $\begin{array}{r}\text { Income } \\
\text { Gap }\end{array}$ & $\begin{array}{r}\text { Total } \\
\text { Expenditure }\end{array}$ & Food & Clothing & HFAS & HCMS & $\mathrm{TC}$ & RECS & Residence \\
\hline Lowest & -716.89 & -975.76 & -118.71 & -51.37 & -277.06 & 811.71 & -260.09 & 282.33 \\
\hline Low & -574.24 & -538.25 & -108.17 & -66.64 & -262.99 & 530.18 & -275.86 & 219.57 \\
\hline $\begin{array}{r}\text { Lower } \\
\text { Middle }\end{array}$ & -436.49 & -312.48 & -78.64 & -74.13 & -131.52 & 272.39 & -228.57 & 180.15 \\
\hline Middle & -68.10 & 123.98 & -43.52 & -68.36 & 7.17 & 53.47 & -108.36 & 10.99 \\
\hline $\begin{array}{r}\text { Upper } \\
\text { Middle }\end{array}$ & -162.67 & 311.78 & 52.26 & 10.13 & 18.81 & -416.96 & 30.86 & -162.18 \\
\hline High & 829.67 & 702.70 & 136.02 & 27.48 & 216.67 & -653.34 & 333.22 & 7.46 \\
\hline Highest & 1128.73 & 688.03 & 160.79 & 222.90 & 428.93 & -597.44 & 508.81 & -538.33 \\
\hline
\end{tabular}

Table 2. Calculation of time factor $\alpha_{t}$

\begin{tabular}{|c|c|c|c|c|c|c|c|c|}
\hline Year & $\begin{array}{l}\text { Total } \\
\text { Expenditure }\end{array}$ & Food & Clothing & HFAS & HCMS & $\mathrm{TC}$ & RECS & Residence \\
\hline 2004 & -425.43 & -448.51 & -27.98 & -35.98 & -72.99 & 153.19 & 16.44 & 55.68 \\
\hline 2005 & -593.89 & -388.20 & -42.24 & -48.89 & -37.60 & 21.01 & -38.80 & -32.45 \\
\hline 2006 & 142.68 & -300.15 & -19.49 & 34.51 & -61.14 & 463.64 & 47.88 & 5.73 \\
\hline 2007 & 187.96 & -294.89 & -6.80 & 84.12 & 38.28 & 328.25 & 21.28 & 7.13 \\
\hline 2008 & 317.90 & 96.58 & -27.57 & 7.39 & 39.65 & -190.83 & 31.00 & 234.55 \\
\hline 2009 & 565.92 & 753.84 & 72.71 & 8.52 & 74.45 & -317.76 & -3.67 & 1.310 \\
\hline 2010 & -195.14 & 581.33 & 51.38 & -49.68 & 19.34 & -457.51 & -74.13 & -271.95 \\
\hline
\end{tabular}

Table 3. Period to period growth rate of time factor $\alpha_{t}$

\begin{tabular}{ccccccccc}
\hline Year & $\begin{array}{c}\text { Total } \\
\text { Expenditure }\end{array}$ & Food & Clothing & HFAS & HCMS & TC & RECS & Residence \\
2005 & -0.395 & 0.134 & -0.510 & -0.359 & 0.485 & -0.863 & -3.360 & -1.583 \\
2006 & 1.240 & 0.227 & 0.539 & 1.706 & -0.626 & 21.068 & 2.234 & 1.177 \\
2007 & 0.317 & 0.0175 & 0.652 & 1.438 & 1.626 & -0.292 & -0.556 & 0.244 \\
2008 & 0.691 & 1.328 & -3.055 & -0.912 & 0.036 & -1.581 & 0.457 & 31.896 \\
2009 & 0.780 & 6.805 & 3.637 & 0.153 & 0.878 & -0.665 & -1.118 & -0.994 \\
2010 & -1.344 & -0.229 & -0.293 & -6.831 & -0.740 & -0.440 & -19.199 & -208.595 \\
\hline
\end{tabular}

consumption from 2004 to 2009. In 2010, total expenditure and expenses in each category tend to come down because of the catastrophic flood damage which is rarely seen in the history. For instance, values of $\alpha_{t}$ in HFAS, TC, RECS and Residence are less than 0 , which shows that residents do not dare to spend money in this period. To analysis the direction of expenses in each category, we calculate the period to period growth rate of time factor $\alpha_{t}$ as Table 3. It is very straight-forward that residence consumption fluctuated remarkably after 2007. Reason is that the building of the International Tourism Island leads to a house-price boom, which reflects the unreasonable economic structure.

\section{Conclusion}

From the above analysis, we can conclude that urban residents' living standards have been improved in Hainan in recent years. But income factor remains an important factor that affects urban residents' consumption structure. Widening of income gap has significant effects on consumption. Narrowing the income distribution gap is essential for supporting consumption and adjusting consumption structure. The government should hold firmly the great opportunity of enhancing the building of the International Tourism Island to the national strategy, 
make use of superiority in various respects in Hainan, widen finance investments, speed up the adjustment of the economic structure, increase employment and raise residents' income.

\section{Acknowledgements}

This work is partially supported by Hainan Provincial Natural Science Fund (112001), Young Teacher Funded Research Project of Hainan Normal University (QN1233) and the Scientific Research Foundation of Yunnan Province Education Committee (2011C120).

\section{REFERENCES}

[1] A. Blinder, "The Relationship between Distribution Effects and the Consumption," The Journal of Political Economy, Vol. 132, No. 3, 2002, pp. 447-476.

[2] D. Valley, A. Philips, "Studies in Inequality of Income and Consumption Function: Some Cross-Country Results," The Journal of Political Economy, Vol. 133, No. 6, 2003, pp. 132-157.

[3] P. Musgrove, "Income Distribution in countries During the Period of Economic Reform and Globalization," The Journal of Political Economy, Vol. 102, No. 3, 2005, pp. 34-105.

[4] F. Sun, D. H. Yi, "Analysis of Income Distribution Effect on Chinese Urban Households Consumption Structure," Statistical Research, No. 3, 2000, pp. 9-15.

[5] J. Li, "Quantitative Analysis of Income Gap Effects on Consumption Demand," Journal of Quantitative \& TechnicalEconomics, No. 9, 2003, pp. 5-11.

[6] Y. Zhang, R.. D. Hu, "Analysis of Chinese Residents' Income Differentials and Consume Demand," Forecasting, Vol. 22, No. 2, 2003, pp. 3-6.

[7] L. Y. Chen, "Income Distribution and Underconsumption," Inquiry into Economic Issues, No. 4, 2005, pp. 23-25.

[8] Hainan bureau of statist, "Hainan Statistical Yearbook," Chinese Statistics Press, Beijing, 2005-2011.

[9] H. Cheng, "Analysis of Panel Data," In: H. Cheng, Simple Regression with Variable Intercepts, Cambridge University Press, New York, 2003, pp. 27-57.

[10] D. H. Yi, "Data Analysis and Eviews Application," In: D. H. Yi, Panel Data Model, Chinese Statistics Press, Beijing, 2002, pp. 201-204. 